\title{
A unique case of extrarenal calyces and associated vascular variations in an adult female cadaver
}

\author{
S. Ahuja, N. Maglasang, Y. Tan® D, D.T. Daly® \\ Department of Surgery, Centre for Anatomical Science and Education, Saint Louis University School of Medicine, \\ Saint Louis, MO, United States
}

[Received: 18 August 2021; Accepted: 24 September 2021; Early publication date: 7 October 2021]

The following urogenital and vascular anomalies were observed in the left kidney of an 81-year-old female cadaver during routine dissection: three extrarenal calyces; an accessory renal artery originating directly from the abdominal aorta; and a circumaortic renal vein.

The typical renal anatomical structures were identified, from anterior to posterior, as the renal vein, renal artery, and ureter appearing near the hilum of the left kidney. After closer examination, three extrarenal calyces were observed exiting from the hilum of the left kidney to form the pelvis, then narrowed and became the ureter which descended $21.5 \mathrm{~cm}$ to empty into the bladder. The accessory renal artery originated from the lateral aspect of the abdominal aorta $7.3 \mathrm{~cm}$ below the aortic origin of the left renal artery. A corresponding accessary renal vein, identified as a circumaortic vein, left the hilum $4.5 \mathrm{~cm}$ below the left renal vein and travelled posterior to the abdominal aorta to drain into the inferior vena cava. Extrarenal calyces are rare among urogenital tract variations. They can be associated with embryological abnormalities such as renal ectopia, horseshoe kidney or malrotation as well as clinical manifestations such as pelviureteric junction obstruction and hydronephrosis. Compression of the accessory renal artery can cause decreased blood flow to the inferior pole of the left kidney, thereby causing fibrosis, atrophy, or renal failure. The retro-aortic path of the circumaortic renal vein has been associated with posterior nutcracker phenomenon, haematuria, left renal vein thrombus formation, and renal vein hypertension. This unique combination of a collecting system anomaly and extrarenal vessel variations could have significant implications in abdominal surgery. (Folia Morphol 2022; 81, 4: 1072-1078)

Key words: renal vein, renal artery, kidney, extrarenal calyces, congenital abnormalities of the kidney and urinary tract

\section{INTRODUCTION}

Congenital abnormalities of the kidney and urinary tract (CAKUT) encompass variations of the kidney, ureter, bladder, and urethra and can range in clini- cal manifestation from asymptomatic to severe [40]. Normally, blood passes through the nephron, the functional unit of the kidney, and undergoes filtration, reabsorption, and secretion to produce urine [10]. The

Address for correspondence: D.T. Daly, Assistant Professor, Department of Surgery, Centre for Anatomical Science and Education, Saint Louis University School of Medicine, Saint Louis, MO 63104, USA, tel: 314-977-8027, fax: 314-977-5127, e-mail: daniel.daly@health.slu.edu 
urine then drains into a collecting duct which empties into a minor calyx; two to three minor calyces empty into one major calyx which collectively drains into the intrasinusal renal pelvis, the broadest and uppermost portion of the ureter [10]. A normal ureter then travels approximately $25 \mathrm{~cm}$ to empty into the posterolateral aspect of the bladder [10]. An extrarenal calyx (ERC), described as rare among CAKUT variations, occurs when the major calyces are located outside of the renal parenchyma [36]. The number and length of the ERC can vary, and the prevalence is not well described in the literature $[19,29,36]$. Plain radiography and ultrasonography are reported to be unhelpful ERC diagnostic tools, though the use of contrast in excretory urography can provide relevant information regarding the kidneys, ureters, and bladder [31]. Retrograde pyelography can detect the ERC being unsupported by the renal parenchyma, but that may be incorrectly diagnosed as hydronephrosis [19]. Similarly, abdominal computed tomography imaging can lead to an incorrect diagnosis of lymphadenopathy [45]. The limitations of imaging techniques, coupled with the rarity of an extrarenal pelvicalyceal collecting system, often precludes a pre-operative ERC diagnosis, meaning that it is usually an incidental finding [19]. Increased awareness of ERC can lead to an increase in correct pre-operative diagnoses, thereby lessening the chance of damaging the pelvicalyceal system and surrounding vasculature during surgery.

Inconsistent nomenclature describing additional renal arteries is pervasive in the literature with use of terms including aberrant, accessory, anomalous, multiple, supernumerary, supplementary, and polar arteries $[1,18]$. This report utilizes the definition of additional renal arteries as established by Holden et al. [23] which categorizes the additional artery as an accessory renal artery, which acts as a branch of the renal artery and supplies blood to a renal segment [11, 23]. Accessory renal arteries typically arise from the abdominal aorta, have a reported frequency of $24 \%$ and are bilateral in roughly $10 \%$ of the population $[20,44]$. The incidence decreases with each additional accessory artery, such that the presence of three accessory renal arteries has only been identified in $0.2-2.0 \%$ of specimens [26]. Possible clinical manifestations depend on the arterial relationship to surrounding structures, such as the ureter and gonadal vessels [42].

The importance of renal venous drainage is underscored by two meta-analyses which investigate the most prevalent variations of this system $[24,41]$.
Right-sided renal vein abnormalities are reported more commonly than left-sided, perhaps because the inferior vena cava (IVC) is predominantly formed by right-sided embryological structures [24]. However, there is abundant variation attributed to the left renal vein, likely due to its complex embryological origin $[34,41]$. These left sided variations include a retroaortic vein, wherein a single renal vein travels posterior to the abdominal aorta, and an additional renal vein that travels anterior to the abdominal aorta to independently drains into the IVC [41]. The renal vein variation observed in the current case study is a circumaortic vein in which a kidney is drained by two renal veins that empty into the IVC; one vein that follows the normal anatomical course anterior to the abdominal aorta and another travelling posterior to the abdominal aorta $[4,41]$. Similar to the arterial variations, the effects of left renal vein variations depend on relationships to neighbouring structures, such as the abdominal aorta, left gonadal vein, left suprarenal vein, and left inferior phrenic vein.

\section{CASE REPORT}

An 81-year-old female body was received through the Saint Louis University Gift of Body Programme of the Centre for Anatomical Science and Education (CASE) with signed informed consent from the donor. The CASE gift body program abides by the rules set forth by the Uniform Anatomical Gift Act.

As perirenal fat was cleared in routine dissection, the anticipated hilar structures were observed in the left kidney, from anterior to posterior, as the renal vein, renal artery, and the continuation of the urinary collecting system which, in this case, were the ERC (Figs. 1, 2). The lengths of the three ERC, measured from the apex of the medullary pyramids to the renal pelvis, were $3 \mathrm{~cm}, 1 \mathrm{~cm}$, and $2 \mathrm{~cm}$, from superior to inferior. Once the ERC united, the left ureter descended $21.5 \mathrm{~cm}$ over the left psoas major muscle and the left common iliac artery to empty into the posterolateral aspect of the bladder (Fig. 1).

Further dissection of the hilum revealed two vascular variations: an accessory renal artery and a circumaortic vein. After travelling $2.6 \mathrm{~cm}$ from the aorta, the renal artery displayed a prehilar branching pattern to supply four of the five renal segments including the apical, anterior superior, anterior inferior, and the posterior segments (Fig. 2). The accessary renal artery emerged from the lateral aspect of the abdominal aorta $7.3 \mathrm{~cm}$ below the renal artery and travelled 

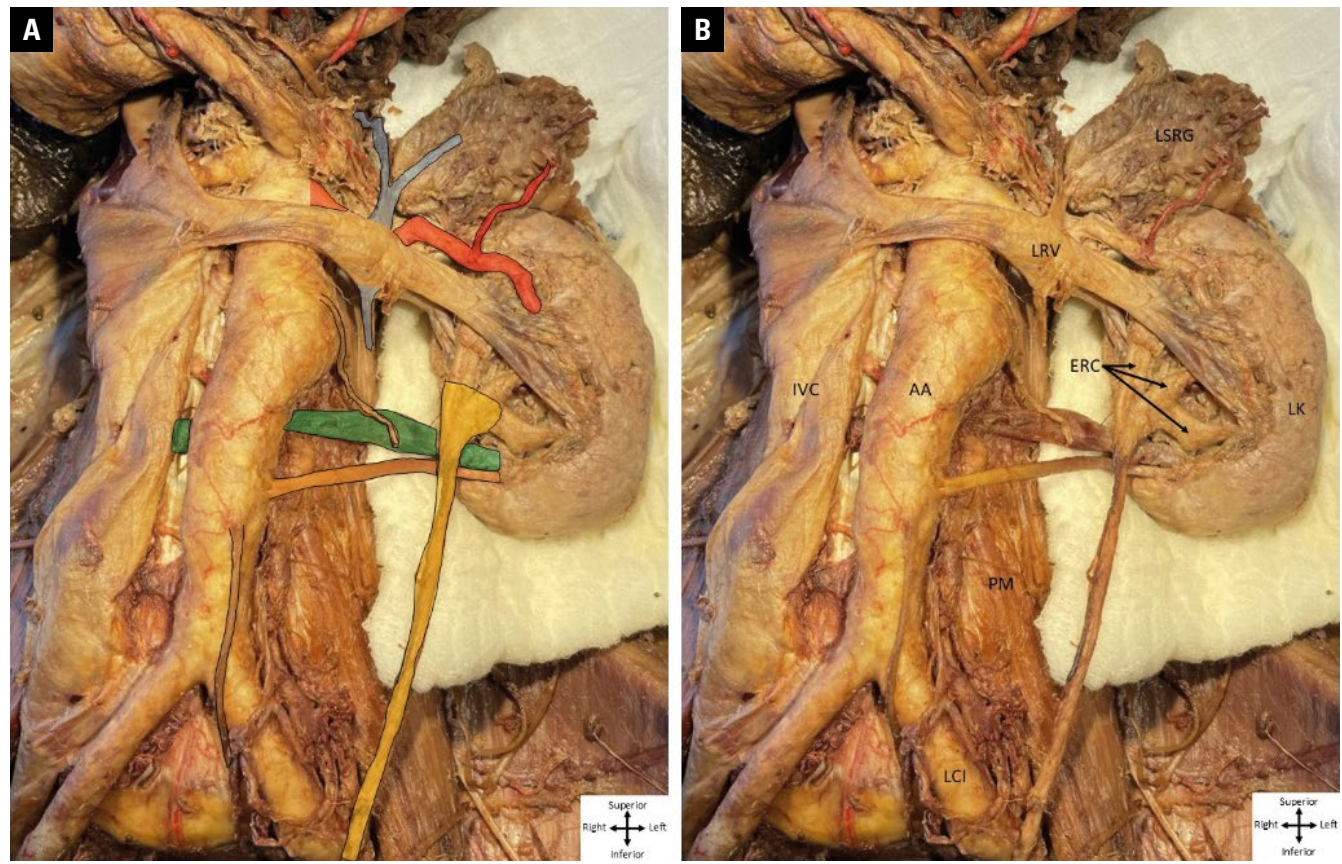

Figure 1. Anterior view of the kidney and associated structures; A. The important anatomical structures of this case study. The three extrarenal calyces (ERC) (yellow) united to form the renal pelvis and ureter, which descended anterior to the circumaortic vein (green), accessory renal artery (orange), psoas major (PM) muscle and the left common iliac artery (LCI) to drain into the bladder. The left renal artery (red) travelled parallel and superior to the left renal vein (LRV), giving off the inferior suprarenal artery to the left suprarenal gland (LSRG), then branching into segmental arteries to supply the left kidney (LK). The LRV received three tributaries (blue): the left suprarenal and left inferior phrenic veins which formed a common trunk before draining into the LRV, and the left ovarian vein (cut) which travelled superiorly to drain into the LRV. There were no veins observed joining with the circumaortic vein as it travelled from the renal hilum to the inferior vena cava (IVC); B. Anatomical relationships between the anatomical variants and surrounding structures. The following structures were observed in the left hilum from anterior to posterior: renal vein, renal artery, and ERC. Two structures were observed, from superior to inferior, at the lower aspect of the left hilum: the circumaortic vein, which travelled posterior to the abdominal aorta (AA) draining into the IVC, and the accessory renal artery. Both the circumaortic vein and accessory renal artery travelled posterior to the ureter.

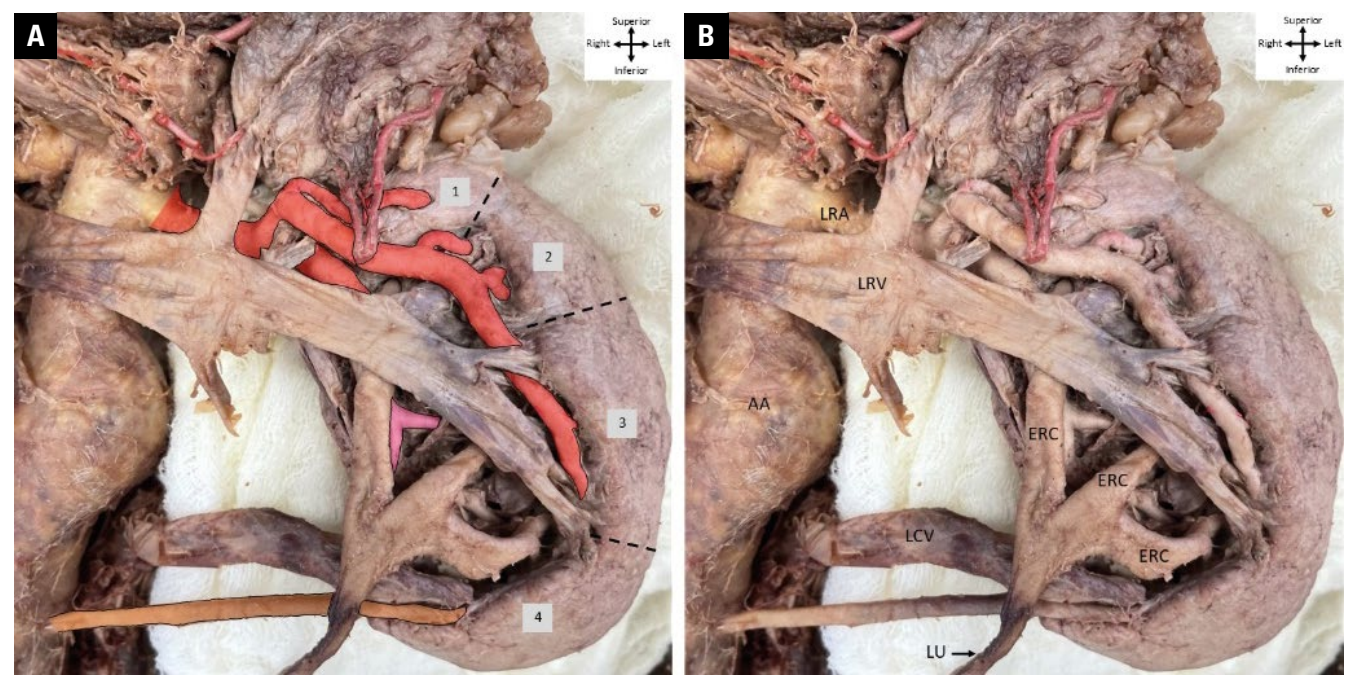

Figure 2. Anterior view of the renal hilum; A. The important anatomical structures of this case study. The left renal artery (LRA) (red) originated from the abdominal aorta $(A A)$ and underwent prehilar branching to supply the three superiormost anterior renal segments (labelled as $1,2,3$ ), the second of which received two segmental branches. The renal artery also sent a branch (pink) to the posterior renal segment. The accessory renal artery (orange) also originated from the AA and entered the left renal hilum to supply the inferior renal segment (4) of the anterior aspect of the left kidney; B. Anatomical relationships between the anatomical variants and surrounding structures. The circumaortic vein and accessory renal artery traveled posterior to the ureter. The arterial branch to the posterior renal segment traveled posterior to the renal vein and extrarenal calyx (ERC); LRV — left renal vein; LU — left ureter; PM — psoas major; LCV — left circumaortic vein. 
posterior to the ureter to enter the inferior aspect of the hilum and supply the inferior renal segment (Figs. 1, 2).

The circumaortic vein, described as the retro-aortic left accessary renal vein, was observed leaving the renal hilum $4.5 \mathrm{~cm}$ below the left renal vein and was parallel and superior to the accessory renal artery before draining into the IVC (Figs. 1, 2). No venous tributaries entered the circumaortic vein, though the typical arrangement of venous drainage was observed as the left ovarian vein, the left inferior phrenic vein, and the left suprarenal vein draining into the left renal vein (Fig. 2).

Although multiple variations were present in the left pelvicalyceal collecting system that could lead to various pathologies, none of the indicated pathologies were noted possibly due to limitations in the provided medical history. There were no vascular or urogenital variations observed in the right kidney.

\section{DISCUSSION}

\section{Extrarenal calyces of the left kidney}

The embryological cause of ERC is currently unclear, but it is likely due to an error during the development of the metanephros [5, 31]. Formation of the urinary tract begins as the urogenital ridge gives rise to the nephrogenic cord [37]. The nephrogenic cord differentiates into the pronephros, comprised of pronephric ducts and intermediate mesoderm, which has been traditionally described as the non-functional kidney in humans [37]. It should be noted that a 2019 study by de Bakker et al. [8] demonstrates that humans may not experience a pronephros proper stage, which is defined as a time when the renal corpuscle is separate from the tubular system within a nephron [8]. Regardless, the pronephric ducts become the mesonephric duct which, along with intermediate mesoderm, forms the mesonephric system [37]. The mesonephros is the functioning renal unit of the embryo; as development continues, many of its parts degenerate while the distal end of the mesonephric duct persists to form the ureteric bud [37]. The ureteric bud and the metanephric blastema, formed from the intermediate mesoderm, reciprocally induce one another to differentiate and form the metanephros, or the adult urinary system [27]. Specifically, the ureteric bud forms the collecting ducts, minor and major calyces, and the ureter, so a disruption in its differentiation signalling cascade could lead to extra-renal development of the pelvicalyceal system $[5,31]$.
Instances of ERC are likely underreported as there are limited diagnostic tools available to accurately identify this CAKUT variation, thereby often incorrectly diagnosing the ERC or making it an incidental finding during autopsy or operation. An accurate diagnosis of ERC and other urogenital malformations is imperative as CAKUT variations are the most frequent congenital birth defect and cause about $7 \%$ of adult end-stage renal disease globally [5]. Extrarenal calyces are also associated with calculus formation and surgical complications [13].

\section{Left accessory renal artery}

The embryological origin of additional renal arteries is currently unclear, though the debate appears to be centred on whether the embryological aorta is capable of branching after extra mesonephric arteries obliterate. The current hypothesis related to this embryological development is Felix's ladder theory, in which two of the nine lateral mesonephric arteries persist to become the renal and gonadal arteries; however, recent research suggests that the mesonephric ladder is actually obliterated prior to the metanephric system's ascension and the aorta provides new segmental yet asymmetrical branches to supply the metanephros $[22,25]$.

Additional renal arteries can be further described as aberrant or accessory, two terms which have been defined in previous literature as to originate from an aortic ostium separate from that of the renal artery, though the aberrant type enters the renal parenchyma outside of the renal hilum and the accessory type enters at the hilum $[23,33]$. The additional renal artery in this case study was observed originating from the abdominal aorta and entering the renal hilum, hence its categorisation as an accessory renal artery [17, 35].

The presence of this artery can cause congenital hydronephrosis and ureteral obstructions and can also pose a significant risk factor during endoscopic surgery and retroperitoneal surgery. Furthermore, compression of this artery can be associated with ischaemia of the lower renal pole which could subsequently damage a renal calyx and cause urine extravasation $[21,35,39]$. It has also been postulated that accessory renal arteries increase the risk of hypertension $[2,16]$.

\section{Left circumaortic renal vein}

The circumaortic renal vein is one of numerous possible anomalies of the renal collar, an embryolog- 
ical structure which persists to form part of the renal IVC and the left renal vein [14]. An embryo consists of three venous systems: the vitelline veins that drain the gut; the umbilical veins that drain the placenta; and the cardinal system that drains the remaining embryonic tissue [14]. The cardinal system is divided into anterior cardinal, posterior cardinal, supracardinal and subcardinal veins [9]. The posterior cardinal, supracardinal and subcardinal veins form anastomoses with one another, thereby creating a renal collar which spans the length between the developing left kidney and IVC and surrounds the abdominal aorta $[3,9,14]$. The collar has two limbs, ventral and dorsal; the ventral limb persists to become part of the IVC and the left renal vein, while the dorsal limb should regress [30]. Persistence of both the ventral and dorsal limbs of the renal collar results in one renal vein which is anterior to the aorta and a second, circumaortic vein that is posterior to the aorta [30]. The collar does not have to be present at a single vertebral level, so it is possible for the circumaortic vein to be inferior to the hilar vein as is seen in the current case [30].

Previous studies show the prevalence of circumaortic veins ranging between $0.3 \%$ and $30 \%$, but these studies have not documented the prevalence of whether the gonadal vein drains into the circumaortic or renal vein $[7,41]$. In the current case, the left gonadal, left inferior phrenic, and left suprarenal veins drain into the left renal vein and the circumaortic vein did not receive any tributaries, though there have been reports of the left gonadal vein draining into the circumaortic vein [30]. Both of these drainage pathways are possible likely because the embryological subcardinal veins, which contribute to the dorsal and ventral limbs of the renal collar, are also the source of the gonadal vein [9]. Regardless of where the left gonadal vein drains, both scenarios include the circumaortic vein traveling posterior to the aorta to drain into the IVC. Potential implications of the retro-aortic path of this vein include difficulties during renal transplant as well as compression between the vertebral column and the aorta leading to a posterior nutcracker phenomenon or, if the patient is displaying symptoms such as renal vein hypertension, haematuria and low back pain, posterior nutcracker syndrome $[6,12,15,28,32,34,38,43]$.

\section{CONCLUSIONS}

Post-mortem urogenital and vascular anomalies were observed on the left kidney of an 81-year-old female cadaver: three ERC, an accessory renal artery, and a circumaortic renal vein. A review of previous literature suggests that the CAKUT variation of ERC is more prevalent than previously believed; while ERC may not be the most obvious diagnosis using current imaging techniques, it should be considered by clinicians when investigating pathologies like hydronephrosis and performing renal transplantation

\section{Acknowledgements}

The authors would like to thank Clay McDonough, $M D$, for his assistance in reviewing the manuscript and providing useful insights in the revision process.

\section{Funding}

This study was supported by the Centre for Anatomical Science and Education, Saint Louis University School of Medicine, Saint Louis, MO, United States.

\section{Conflict of interest: None declared}

\section{REFERENCES}

1. Ahuja $S$, Sullivan $H$, Noller $M$, et al. A unique case of incomplete bifid ureter and associated arterial variations. Case Rep Urol. 2021; 2021: 6655813, doi: 10.1155/2021/6655813, indexed in Pubmed: 33489410.

2. Bakker J, Beek FJ, Beutler JJ, et al. Renal artery stenosis and accessory renal arteries: accuracy of detection and visualization with gadolinium-enhanced breath-hold MR angiography. Radiology. 1998; 207(2): 497-504, doi: 10.1148/ radiology.207.2.9577501, indexed in Pubmed: 9577501.

3. Bass JE, Redwine MD, Kramer LA, et al. Spectrum of congenital anomalies of the inferior vena cava: cross-sectional imaging findings. Radiographics. 2000; 20(3): 639-652, doi: 10.1148/radiographics.20.3.g00ma09639, indexed in Pubmed: 10835118.

4. Beckmann CF, Abrams HL. Circumaortic venous ring: incidence and significance. AJR Am J Roentgenol. 1979; 132(4): 561-565, doi: 10.2214/ajr.132.4.561, indexed in Pubmed: 106686.

5. Capone VP, Morello W, Taroni F, et al. Genetics of congenital anomalies of the kidney and urinary tract: the current state of play. Int J Mol Sci. 2017; 18(4), doi: 10.3390/ ijms18040796, indexed in Pubmed: 28398236.

6. Cuéllar i Calàbria H, Quiroga Gómez S, Sebastià Cerqueda C, et al. Nutcracker or left renal vein compression phenomenon: multidetector computed tomography findings and clinical significance. Eur Radiol. 2005; 15(8): 1745-1751, doi: 10.1007/s00330-005-2688-y, indexed in Pubmed: 15742169.

7. Davis CJ, Lundberg GD. Retroaortic left renal vein, a relatively frequent anomaly. Am J Clin Pathol. 1968; 50(6): 700-703, doi: 10.1093/ajcp/50.6.700, indexed in Pubmed: 4881947.

8. de Bakker BS, van den Hoff MJB, Vize PD, et al. The pronephros; a fresh perspective. Integr Comp Biol. 2019; 
59(1): 29-47, doi: 10.1093/icb/icz001, indexed in Pubmed: 30649320

9. Eldefrawy A, Arianayagam M, Kanagarajah P, et al. Anomalies of the inferior vena cava and renal veins and implications for renal surgery. Cent European J Urol. 2011; 64(1): 4-8, doi: 10.5173/ceju.2011.01.art1, indexed in Pubmed: 24578852.

10. Ellis H. The Anatomy of the Kidney and Ureter. Surgery (Oxford). 2002; 20(9): 201-203, doi: 10.1383/ surg.20.9.201.14534.

11. Fine $\mathrm{H}$, Keen $E N$. The arteries of the human kidney. J Anat. 1966; 100(Pt 4): 881-894, indexed in Pubmed: 5969982.

12. Fluckiger TA, Eapen AS, Bhattal GK, et al. Retroaortic left renal vein - developmental and clinical implications. Int J Anat Var. 2016; 9: 13-17.

13. Gandhi KR, Chavan S. Revisiting the morphology of pelvicalyceal system in human cadaveric kidneys with a systematic review of literature. Asian J Urol. 2019; 6(3): 249-255, doi: 10.1016/j.ajur.2018.12.006, indexed in Pubmed: 31297316.

14. Ghandour A, Partovi S, Karuppasamy K, et al. Congenital anomalies of the IVC-embryological perspective and clinical relevance. Cardiovasc Diagn Ther. 2016; 6(6): 482-492, doi: 10.21037/cdt.2016.11.18, indexed in Pubmed: 28123970.

15. Gibo M, Onitsuka H. Retroaortic left renal vein with renal vein hypertension causing hematuria. Clin Imaging. 1998; 22(6): 422-424, doi: 10.1016/s08997071(98)00067-9.

16. Glodny B, Cromme S, Wörtler K, et al. A possible explanation for the frequent concomitance of arterial hypertension and multiple renal arteries. Med Hypotheses. 2001; 56(2): 129-133, doi: 10.1054/mehy.2000.1206, indexed in Pubmed: 11425275.

17. Graves FT. The arterial anatomy of the congenitally abnormal kidney. Br J Surg. 1969; 56(7): 533-541, doi: 10.1002/ bjs.1800560717, indexed in Pubmed: 5794973.

18. Gulas E, Wysiadecki G, Szymański J, et al. Morphological and clinical aspects of the occurrence of accessory (multiple) renal arteries. Arch Med Sci. 2018; 14(2): 442-453, doi: 10.5114/aoms.2015.55203, indexed in Pubmed: 29593819.

19. Gupta T, Goyal SK, Aggarwal A, et al. Extrarenal calyces: a rare renal congenital anomaly. Surg Radiol Anat. 2015; 37(4): 407-410, doi: 10.1007/s00276-014-1349-8, indexed in Pubmed: 25031125.

20. Gupta A, Tello R. Accessory renal arteries are not related to hypertension risk: a review of MR angiography data. AJR Am J Roentgenol. 2004; 182(6): 1521-1524, doi: 10.2214/ ajr.182.6.1821521, indexed in Pubmed: 15150000.

21. Gutiérrez-Calzada JL, Ramos-Titos J, González-Bonilla $J A$, et al. Caliceal fistula formation following renal transplantation: management with partial nephrectomy and ureteral replacement. J Urol. 1995; 153(3 Pt 1): 612-614, doi: 10.1097/00005392-199503000-00015, indexed in Pubmed: 7861495.

22. Hinata N, Suzuki R, Ishizawa A, et al. Fetal development of the mesonephric artery in humans with reference to replacement by the adrenal and renal arteries. Ann Anat.
2015; 202: 8-17, doi: 10.1016/j.aanat.2015.07.005, indexed in Pubmed: 26335195.

23. Holden A, Smith A, Dukes P, et al. Assessment of 100 live potential renal donors for laparoscopic nephrectomy with multi-detector row helical CT. Radiology. 2005; 237(3): 973-980, doi: 10.1148/radiol.2373041303, indexed in Pubmed: 16304115.

24. Hostiuc S, Rusu MC, Negoi I, et al. Anatomical variants of renal veins: A meta-analysis of prevalence. Sci Rep. 2019; 9(1): 10802, doi: 10.1038/s41598-019-47280-8, indexed in Pubmed: 31346244.

25. Isogai S, Horiguchi M, Hitomi J. The para-aortic ridge plays a key role in the formation of the renal, adrenal and gonadal vascular systems. J Anat. 2010; 216(6): 656-670, doi: 10.1111/j.1469-7580.2010.01230.x, indexed in Pubmed: 20579173.

26. Jamkar AA, Khan B, Joshi DS. Anatomical study of renal and accessory renal arteries. Saudi J Kidney Dis Transpl. 2017; 28(2): 292-297, doi: 10.4103/1319-2442.202760, indexed in Pubmed: 28352010.

27. Kozlov VM, Schedl A. Duplex kidney formation: developmental mechanisms and genetic predisposition. F1000Res. 2020; 9, doi: 10.12688/f1000research.19826.1, indexed in Pubmed: 32030122.

28. Kurklinsky AK, Rooke TW. Nutcracker phenomenon and nutcracker syndrome. Mayo Clin Proc. 2010; 85(6): 552-559, doi: $10.4065 / \mathrm{mcp} .2009 .0586$, indexed in Pubmed: 20511485.

29. Looney W, Dodd D. An ectopic (pelvic) completely fused (cake) kidney associated with various anomalies of the abdominal viscera. Ann Surg. 1926; 84(4): 522-524, doi: 10.1097/00000658-192684040-00008.

30. Malaki M, Willis AP, Jones RG. Congenital anomalies of the inferior vena cava. Clin Radiol. 2012; 67(2): 165-171, doi: 10.1016/j.crad.2011.08.006, indexed in Pubmed: 22070941.

31. Malament M, Schwartz B, Nagamatsu GR. Extrarenal calyces: their relationship to renal disease. Am J Roentgenol Radium Ther Nucl Med. 1961; 86: 823-829.

32. Nishimura Y, Fushiki M, Yoshida $M$, et al. Left renal vein hypertension in patients with left renal bleeding of unknown origin. Radiology. 1986; 160(3): 663-667, doi: 10.1148/ radiology.160.3.3737903, indexed in Pubmed: 3737903.

33. Ozkan U, Oguzkurt L, Tercan F, et al. Renal artery origins and variations: angiographic evaluation of 855 consecutive patients. Diagn Interv Radiol. 2006; 12(4): 183-186, indexed in Pubmed: 17160802.

34. Pandya VK, Patel AS, Sutariya HC, et al. Evaluation of renal vascular anatomy in live renal donors: Role of multi detector computed tomography. Urol Ann. 2016; 8(3): 270-276, doi: 10.4103/0974-7796.184898, indexed in Pubmed: 27453646.

35. Park BS, Jeong TK, Ma SK, et al. Hydronephrosis by an aberrant renal artery: a case report. Korean J Intern Med. 2003; 18(1): 57-60, doi: 10.3904/kjim.2003.18.1.57, indexed in Pubmed: 12760271.

36. Rajendran S, Cho A, Mishra P, et al. Hydronephrotic kidney with multiple extra-renal calyces. Ann R Coll Surg Engl. 2017; 99(8): e219-e220, doi: 10.1308/rcsann.2016.0287, indexed in Pubmed: 29046082. 
37. Rehman S, Ahmed D. Embryology, Kidney, Bladder, and Ureter. StatPearls, Treasure Island 2020.

38. Russo D, Minutolo R, laccarino V, et al. Gross hematuria of uncommon origin: the nutcracker syndrome. Am J Kidney Dis. 1998; 32(3): E3, doi: 10.1053/ajkd.1998.v32. pm10074588, indexed in Pubmed: 10074588.

39. Sampaio F. Vascular anatomy at the ureteropelvic junction. Urol Clin North Am. 1998; 25(2): 251-258, doi: 10.1016/ s0094-0143(05)70012-4.

40. Sanna-Cherchi S, Ravani P, Corbani V, et al. Renal outcome in patients with congenital anomalies of the kidney and urinary tract. Kidney Int. 2009; 76(5): 528-533, doi: 10.1038/ki.2009.220, indexed in Pubmed: 19536081.

41. Satyapal KS, Kalideen JM, Haffejee AA, et al. Left renal vein variations. Surg Radiol Anat. 1999; 21(1): 77-81, doi: 10.1007/BF01635058, indexed in Pubmed: 10370998 .
42. Singh G, Ng YK, Bay BH. Bilateral accessory renal arteries associated with some anomalies of the ovarian arteries: a case study. Clin Anat. 1998; 11(6): 417-420, doi: 10.1002/ (SICI) 1098-2353(1998)11:6<417::AID-CA8>3.0.CO;2-L, indexed in Pubmed: 9800922.

43. Skeik N, Gloviczki P, Macedo TA. Posterior nutcracker syndrome. Vasc Endovascular Surg. 2011; 45(8): 749-755, doi: 10.1177/1538574411419376, indexed in Pubmed: 21890560

44. Standring S, Gray Ha. Gray's anatomy: the anatomical basis of clinical practice. 40 ed. Churchill Livingstone, Edinburgh, Scotland 2008.

45. Turner RJ, Young SW, Castellino RA. Dynamic continuous computed tomography: study of retroaortic left renal vein. J Comput Assist Tomogr. 1980; 4(1): 109-111, doi: 10.1097/00004728-198002000-00020, indexed in Pubmed: 7354161. 